Check for updates

Cite this: Mater. Adv., 2021, 2, 2000

Received 7th December 2020, Accepted 31st January 2021

DOI: 10.1039/d0ma00961j

rsc.li/materials-advances

\section{Facile assembly and improved photocatalytic activity of a special cuprous oxide/copper fluoride heterojunction induced by graphene oxide $\dagger$}

\author{
Mengya Xi, Wanru Zhang, Zhiyuan Liu, Lixia Qin, Shi-Zhao Kang iD and \\ Xiangqing $\mathrm{Li}$ iD *
}

\begin{abstract}
The simple fabrication of effective-contacted heterojunctional photocatalysts is still a challenge in practical applications. Herein, a special flower-like $\mathrm{Cu}_{2} \mathrm{O} / \mathrm{CuF}_{2}$ heterojunction nanocomposite $\left(\mathrm{Cu}_{2} \mathrm{O} / \mathrm{GO} / \mathrm{CuF}_{2}\right)$ was facilely achieved in situ induced by graphene oxide (GO). The assembly mechanism of the $\mathrm{Cu}_{2} \mathrm{O} / \mathrm{GO} / \mathrm{CuF}_{2}$ nanocomposite was studied by means of ultraviolet-visible spectroscopy, Fourier transform infrared spectroscopy, X-ray powder diffraction, and scanning electron microscopy. It was found that the introduction of $\mathrm{GO}$ can promote the formation of the $\mathrm{Cu}_{2} \mathrm{O} / \mathrm{CuF}_{2}$ heterojunction. Furthermore, the performance of the composite was evaluated via photocatalytic hydrogen production. The results showed that its activity was much higher than those of the other comparisons. The mechanism of photocatalytic hydrogen production over the $\mathrm{Cu}_{2} \mathrm{O} / \mathrm{GO} / \mathrm{CuF}_{2}$ nanocomposite was explored, demonstrating that good light absorption, low interfacial resistance and high charge separation in the special heterojunction induced by GO were responsible for the enhanced performance.
\end{abstract}

\section{Introduction}

As an economical and environmentally friendly strategy, photocatalytic water splitting technology has attracted the attention of researchers because it can convert solar energy into conservable chemical fuels. ${ }^{1,2}$ In this regard, photocatalysts based on semiconductors that can effectively collect and transform light energy are of most interest. ${ }^{3,4}$

As an environmentally friendly and cheap semiconductor with a narrow band gap, cuprous oxide has potential applications in many fields including solar cells, gas sensors, lithium-ion battery and photocatalysis. ${ }^{5}$ In particular, it has attracted wide attention from researchers due to high photocatalytic and photoelectrochemical performances in the water decomposition reaction. ${ }^{6}$ Unfortunately, a high combination of electrons and holes is observed due to the presence of random defects in pure $\mathrm{Cu}_{2} \mathrm{O}$, which will severely limit the photocatalytic process. ${ }^{7}$ Therefore, the design and development of $\mathrm{Cu}_{2} \mathrm{O}$-related photocatalysts with high charge separation and photocatalytic activity are still essential challenges.

School of Chemical and Environmental Engineering, Center of Graphene Research, Shanghai Institute of Technology, 100 Haiquan Road, Shanghai 201418, China.

E-mail:xqli@sit.edu.cn

$\dagger$ Electronic supplementary information (ESI) available. See DOI: 10.1039/ d0ma00961j
In order to effectively decrease charge recombination in semiconductors and improve the catalytic activity, the fabrication of heterojunction structures has been considered as an effective strategy. ${ }^{8}$ Copper fluoride, a wide band-gap positive material with a rutile crystal structure, has been reported as a new type of photocatalyst. ${ }^{9}$ However, copper fluoride easily forms hydrogen bonds with water molecules, thereby reducing the nucleophilicity of fluoride ions. By combining $\mathrm{CuF}_{2}$ and the bis-phosphine ligand, Constantin et al. obtained a new catalyst system, and found that catalytic activity was improved by the introduction of $\mathrm{CuF}_{2}{ }^{10}{ }^{10}$ Casares et al. found that, in the coupling of arylalkoxysilanes, $\mathrm{CuF}_{2}$ greatly accelerated the reaction process so that the catalytic activity was enhanced. ${ }^{11}$

It is known that, by controlling the size and dispersion of the cocatalyst, and establishing the appropriate connection between the cocatalyst and the photocatalyst, the photocatalytic activity can be expected to significantly improve due to the low energy barrier and high charge transfer in the interface. ${ }^{12}$ The simple fabrication of effective-contacted heterojunctional photocatalysts is an effective way to solve the problem. In the various methods used to prepare the junctions (such as the sol-gel method, hydrothermal synthesis, coprecipitation, ball milling, solid phase synthesis, continuous deposition technology, and in situ growth method $^{13}$ ), the heterojunction prepared by in situ synthesis exhibits better performance. ${ }^{14}$ No obvious lattice dislocations or defects were found at the interface synthesized 
using an in situ method compared with that prepared by continuous deposition. ${ }^{15}$ However, an individual heterojunction is easy to coalesce and shows poor dispersibility and low stability.

In recent years, many researchers have conducted extensive research on carbon-based catalysts. ${ }^{16-19}$ As an ideal catalyst support, GO has been widely used to improve the photocatalytic performance of semiconductors such as $\mathrm{TiO}_{2}, \mathrm{ZnO}, \mathrm{CdS}$, and $\mathrm{ZnFe}_{2} \mathrm{O}_{4} \cdot{ }^{20}$ Generally, its enhancement mechanism can be attributed to the following facts: capture and transfer electrons, broaden spectral response range, prevent the agglomeration of nanoparticles, and enhance the adsorption of materials. ${ }^{21}$ Moreover, Pan et al. found that the composition, morphology and energy band structure of tin oxide-reduced graphene oxide nanocomposites can be controlled by GO. ${ }^{22}$ Lei et al. confirmed that GO can change the morphology of the carbonated resorcinolformaldehyde particles and enhance the utilization of micropores, thus obtaining a better supercapacitor performance. ${ }^{23}$ Based on the above analysis, it is feasible to fabricate a special $\mathrm{Cu}_{2} \mathrm{O} / \mathrm{CuF}_{2}$ heterojunction induced by $\mathrm{GO}$ in order to obtain a $\mathrm{Cu}_{2} \mathrm{O}$-based photocatalyst with high charge separation for efficient photocatalytic hydrogen production. To our knowledge, there is no report about a GO-induced $\mathrm{Cu}_{2} \mathrm{O} / \mathrm{CuF}_{2}$ heterojunction for photocatalytic $\mathrm{H}_{2}$ generation.

In this study, via in situ growth, a special $\mathrm{Cu}_{2} \mathrm{O} / \mathrm{CuF}_{2}$ heterojunction is fabricated induced by GO. The morphology, structure, and composition of the target material $\left(\mathrm{Cu}_{2} \mathrm{O} / \mathrm{GO} /\right.$ $\mathrm{CuF}_{2}$ nanocomposite) are studied via SEM, TEM, XRD, FTIR and XPS. The in situ prepared $\mathrm{Cu}_{2} \mathrm{O} / \mathrm{GO} / \mathrm{CuF}_{2}$ nanocomposite shows a better photocatalytic activity for hydrogen production compared with those of the comparisons. In addition, the mechanisms of electron transfer and photocatalytic hydrogen production in the $\mathrm{Cu}_{2} \mathrm{O} / \mathrm{GO} / \mathrm{CuF}_{2}$ nanocomposite are studied.

\section{Experimental section}

\subsection{Assembly of the $\mathrm{Cu}_{2} \mathrm{O} / \mathrm{GO} / \mathrm{CuF}_{2}$ nanocomposite}

$250 \mathrm{mg}$ of $\mathrm{Cu}_{2} \mathrm{O}$ (prepared according to the method in the

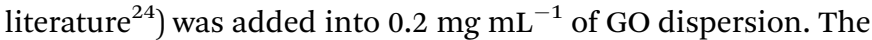
suspension was stirred for $24 \mathrm{~h}$, and then the solid $\left(\mathrm{Cu}_{2} \mathrm{O} / \mathrm{GO}\right)$ was separated centrifugally, washed to neutrality, and placed in a vacuum oven at $60{ }^{\circ} \mathrm{C}$.

$100 \mathrm{mg}$ of $\mathrm{Cu}_{2} \mathrm{O} / \mathrm{GO}$ was suspended in $100 \mathrm{~mL}$ of secondary water, the $\mathrm{pH}$ value of the solution was adjusted to 3 with $0.1 \mathrm{~mol} \mathrm{~L}^{-1}$ of $\mathrm{HCl}$, and then $39 \mathrm{mg}$ of $\mathrm{NaF}$ was added and stirred at room temperature for $6 \mathrm{~h}$. The solid $\left(\mathrm{Cu}_{2} \mathrm{O} / \mathrm{GO} / \mathrm{CuF}_{2}\right.$ nanocomposite) was separated, washed to neutrality, and put in a vacuum oven at $60{ }^{\circ} \mathrm{C}$. The main process is shown in Scheme 1 .

In addition, the comparison, the $\mathrm{Cu}_{2} \mathrm{O} / \mathrm{GO} / \mathrm{CuF}_{2}$ (simply mixed) obtained by simply mixing $\mathrm{Cu}_{2} \mathrm{O}$, GO and $\mathrm{CuF}_{2}$, was also prepared. The procedure was similar to the in situ assembly of the $\mathrm{Cu}_{2} \mathrm{O} / \mathrm{GO} / \mathrm{CuF}_{2}$, except that $\mathrm{NaF}$ was replaced with $\mathrm{CuF}_{2}$.

\subsection{Characterizations}

All samples used in TEM measurements were dispersed into double distilled water to form a suspension. A drop was then

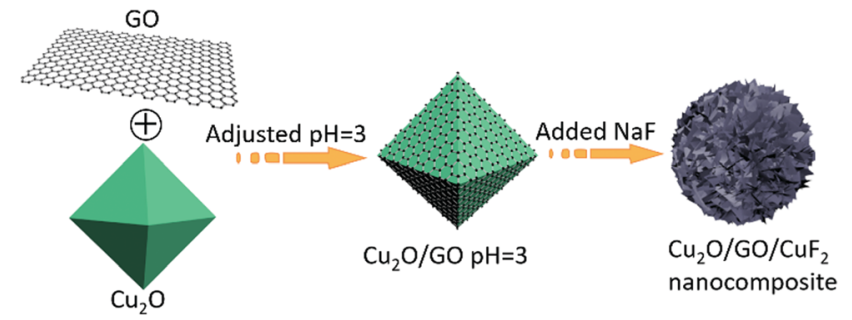

Scheme 1 The synthesis procedure of the $\mathrm{Cu}_{2} \mathrm{O} / \mathrm{GO} / \mathrm{CuF}_{2}$ nanocomposite.

added onto a 230 mesh copper grid with an ultrathin carbon film. The morphology of the sample was taken using a Japanese JEOL JEM-2100F transmission electron microscope at an acceleration voltage of $200 \mathrm{kV}$. The SEM image of the sample was observed using a Japanese S-4800N Hitachi High Technologies scanning electron microscope. The powder X-ray diffraction (XRD) measurements of the sample were recorded on a German Bruker D8 Advance X-ray diffractometer with monochromatic $\mathrm{Cu} \mathrm{K} \alpha$ radiation. The absorption spectra of the catalysts in the $350-700 \mathrm{~nm}$ range were obtained on a UV-3900 spectrophotometer from Japan. Fourier transform infrared spectroscopy (FTIR) was carried out on a Nicolet 6700 FTIR spectrometer from America. X-ray photoelectron spectroscopy was recorded on a Thermo ESCALAB 250 X-ray photoelectron spectrometer made in America using a monochromatic Al $\mathrm{K} \alpha \mathrm{X}$-ray source and an analyzer with an energy of $1486.6 \mathrm{eV}$. The Raman spectrum of the sample was measured on a i-Raman-532S manufactured in America. A Hitachi F-4600 fluorescence spectrophotometer manufactured in Japan was used to measure the steady-state emission.

\subsection{Electrochemical measurements}

The electrochemical measurements of the sample were performed on the CHI660E electrochemical workstation using a conventional three-electrode system at room temperature. The counter electrode was a platinum electrode, $\mathrm{Ag} / \mathrm{AgCl}$ was a reference electrode, and the working electrode was FTO glass coated with the sample. The conductive surface of the cleaned FTO glass $\left(1 \times 1.5 \mathrm{~cm}^{2}\right)$ was covered by the dispersion of sample. After natural drying, it was heat-treated in an oven at $60{ }^{\circ} \mathrm{C}$ to obtain a working electrode. A $0.1 \mathrm{~mol} \mathrm{~L}^{-1} \mathrm{KCl}$ aqueous solution containing $0.01 \mathrm{~mol} \mathrm{~L}^{-1} \mathrm{~K}_{3} \mathrm{Fe}(\mathrm{CN})_{6} / \mathrm{K}_{4} \mathrm{Fe}(\mathrm{CN})_{6}(1: 1)$ was deoxidized and used as an electrolyte. The working electrode was operated at the range of $1 \mathrm{~cm}^{2}$.

\subsection{Measurement of photocatalytic activity}

$10 \mathrm{mg}$ of photocatalyst was suspended in $50 \mathrm{~mL}$ of triethanolamine (TEOA) aqueous solution $\left(V_{\mathrm{TEOA}}: V_{\mathrm{H}_{2} \mathrm{O}}=1: 5\right)$ through stirring to form a uniform dispersion. A top-illuminated photolysis water reactor (CEL-SP2 N, China) containing the above dispersion was purged with high-purity nitrogen to drive away the residual air before lighting. The carrier gas was $99.99 \%$ high-purity nitrogen. A CEL-HXUV300 xenon lamp (300 W) (spectral range in $340-780 \mathrm{~nm}$ ) was as the light source. The hydrogen generated was analyzed using an online gas chromatograph and an external standard method. 


\section{Results and discussion}

\subsection{The assembly of the $\mathrm{Cu}_{2} \mathrm{O} / \mathrm{GO} / \mathrm{CuF}_{2}$ nanocomposite} system

The morphology of the assembled $\mathrm{Cu}_{2} \mathrm{O} / \mathrm{GO} / \mathrm{CuF}_{2}$ nanocomposite system was first characterized. It can be seen from Fig. 1a, without $\mathrm{GO}$, that the synthesized $\mathrm{Cu}_{2} \mathrm{O} / \mathrm{CuF}_{2}$ consists of some lumpy particles without a definite morphology. Additionally, without GO, only by simply mixed $\mathrm{CuF}_{2}$ and $\mathrm{Cu}_{2} \mathrm{O}$, no regular nanoflower-like morphology is observed (simple mixed) (Fig. S1, ESI $\dagger$ ). In contrast, a uniform and nanoflower-like morphology is observed in the image of $\mathrm{Cu}_{2} \mathrm{O} / \mathrm{GO} / \mathrm{CuF}_{2}$ (Fig. 1b). Obviously, the introduction of GO can promote the construction of the nanoflower-shaped $\mathrm{Cu}_{2} \mathrm{O} / \mathrm{CuF}_{2}$ heterojunction. Subsequently, the special $\mathrm{Cu}_{2} \mathrm{O} / \mathrm{CuF}_{2}$ heterostructure has a close relationship with the synthesis method and the fabrication induced by GO. In order to further study the morphology and structure of the $\mathrm{Cu}_{2} \mathrm{O} / \mathrm{GO} / \mathrm{CuF}_{2}, \mathrm{TEM}$ and HRTEM images of the samples were taken. In the TEM image of the $\mathrm{Cu}_{2} \mathrm{O} / \mathrm{GO} / \mathrm{CuF}_{2}$ (Fig. 1c), the flower-like morphology is observed. The flower seems to be with an about $0.4 \mu \mathrm{m}^{2}$ core surrounded by cross-linked nanosheets. In the HRTEM image of $\mathrm{Cu}_{2} \mathrm{O} / \mathrm{GO} / \mathrm{CuF}_{2}$ (Fig. 1d), the lattice spacings of $0.20 \mathrm{~nm}$, $0.50 \mathrm{~nm}$, and $0.42 \mathrm{~nm}$ are assigned to the $\mathrm{Cu}_{2} \mathrm{O}(111),(411)$, (222) crystal planes, the lattice spacings of $0.20 \mathrm{~nm}$ and $0.21 \mathrm{~nm}$ are attributed to the GO (101), (100) crystal planes, and those of $0.36 \mathrm{~nm}$ and $0.31 \mathrm{~nm}$ and $0.28 \mathrm{~nm}$ correspond to the (122), (022), and (-112) crystal planes of $\mathrm{CuF}_{2}$, respectively. The (202) crystal plane of $\mathrm{CuO}$ is also observed, indicating that a small amount of $\mathrm{Cu}_{2} \mathrm{O}$ is oxidized during the synthesis of the composite (due to its low photocatalytic activity and small amount, it was little discussed). Combining the SEM and TEM images (Fig. 1 and Fig. S1, ESI $\dagger$ ), the nanoflower-like $\mathrm{CuF}_{2}$ could grow uniformly on the boundary of the $\mathrm{Cu}_{2} \mathrm{O} / \mathrm{GO}$ (will be further confirmed by the "Element maps" following), indicating that the as-produced $\mathrm{Cu}_{2} \mathrm{O} / \mathrm{GO}$ boundary is a relatively reactive site for the growth of $\mathrm{CuF}_{2}$. Moreover, the morphology and the interface in the $\mathrm{Cu}_{2} \mathrm{O}$ / $\mathrm{GO} / \mathrm{CuF}_{2}$ nanocomposite is still maintained as shown in the HRTEM image even if it was treated by ultrasonic during the

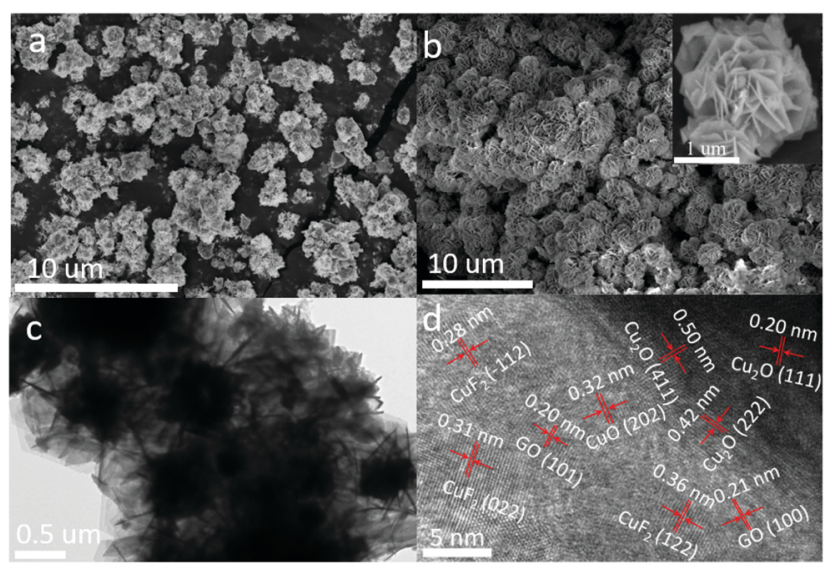

Fig. 1 SEM images of (a) $\mathrm{Cu}_{2} \mathrm{O} / \mathrm{CuF}_{2}$ and (b) $\mathrm{Cu}_{2} \mathrm{O} / \mathrm{GO} / \mathrm{CuF}_{2}$. (c) TEM image and (d) HRTEM image of the $\mathrm{Cu}_{2} \mathrm{O} / \mathrm{GO} / \mathrm{CuF}_{2}$. preparation of sample. The result evidences that the interaction between $\mathrm{Cu}_{2} \mathrm{O}$ and $\mathrm{CuF}_{2}$ is strengthened by forming the special heterojunction, which will facilitate the transfer of photogenerated $\mathrm{e}^{-} / \mathrm{h}^{+}$pairs, and thus photocatalytic performance could be improved. ${ }^{25}$

The XRD patterns of $\mathrm{Cu}_{2} \mathrm{O} / \mathrm{CuF}_{2}$ and $\mathrm{Cu}_{2} \mathrm{O} / \mathrm{GO} / \mathrm{CuF}_{2}$ are shown in Fig. 2. The diffraction peaks at $29.4^{\circ}, 36.2^{\circ}, 42.1^{\circ}$, and $61.3^{\circ}$ correspond to the (110), (111), (200), and (220) crystal faces of $\mathrm{Cu}_{2} \mathrm{O}$, respectively, which match the $\mathrm{PDF}$ card of $\mathrm{Cu}_{2} \mathrm{O}$ (JCPDS 65-3288). Those new characteristic peaks at $30.6^{\circ}, 32.8^{\circ}$, $50.4^{\circ}, 51.1^{\circ}, 54.8^{\circ}$, and $61.3^{\circ}$ are attributed to the (002), $(-111)$, (112), (121), (-113), and (211) crystal faces of $\mathrm{CuF}_{2}$, which match the PDF card of $\mathrm{CuF}_{2}$ (JCPDS 71-1131). It further suggests the formation of the $\mathrm{CuF}_{2}$ phase and not the doping of $\mathrm{F}^{-}$into $\mathrm{Cu}_{2} \mathrm{O}$ crystals. Additionally, no significant GO diffraction peaks are observed in the figure, possibly due to the low content of GO. Although some diffraction peaks of $\mathrm{CuF}_{2}$ can be observed in the XRD pattern of the $\mathrm{Cu}_{2} \mathrm{O} / \mathrm{CuF}_{2}$ (Fig. 2a), the intensity of diffraction peaks is much lower than that in the $\mathrm{Cu}_{2} \mathrm{O} / \mathrm{GO} / \mathrm{CuF}_{2}$. Moreover, the peaks shift towards the direction of the big angle, suggesting that $\mathrm{CuF}_{2}$ could be incorporated into the lattice of $\mathrm{Cu}_{2} \mathrm{O}$ induced by $\mathrm{GO}^{26}$ It is an important indication of the formation of heterojunctions. ${ }^{27}$ As a result, GO can promote the growth of $\mathrm{CuF}_{2}$ and the construction of the $\mathrm{Cu}_{2} \mathrm{O} / \mathrm{CuF}_{2}$ heterostructure. It is consistent with the results in Fig. 1. Though the $\mathrm{CuO}$ phase can be observed in the HRTEM image of the $\mathrm{Cu}_{2} \mathrm{O}$ / $\mathrm{GO} / \mathrm{CuF}_{2}$, it is hardly observed in the XRD pattern of the $\mathrm{Cu}_{2} \mathrm{O}$ / $\mathrm{GO} / \mathrm{CuF}_{2}$. This indicates that the content of $\mathrm{CuO}$ is small. As the activity of $\mathrm{CuO}$ is lower than that of $\mathrm{Cu}_{2} \mathrm{O}$ under the same conditions, ${ }^{28}$ the small amount of $\mathrm{CuO}$ in the nanocomposite is ignored in the discussion of photocatalysis that follows.

According to the results in Fig. 1 and 2, the assembly mechanism of the $\mathrm{Cu}_{2} \mathrm{O} / \mathrm{GO} / \mathrm{CuF}_{2}$ composite system is proposed in Fig. 3. In the assembly process of the $\mathrm{Cu}_{2} \mathrm{O} / \mathrm{GO} /$ $\mathrm{CuF}_{2}$ system, first, the carboxyl groups on the surface of the GO sheet can interact with hydroxyl groups on $\mathrm{Cu}_{2} \mathrm{O}$, and thus GO is easily coated on the surface of $\mathrm{Cu}_{2} \mathrm{O}$. After adjusting to $\mathrm{pH}=3$

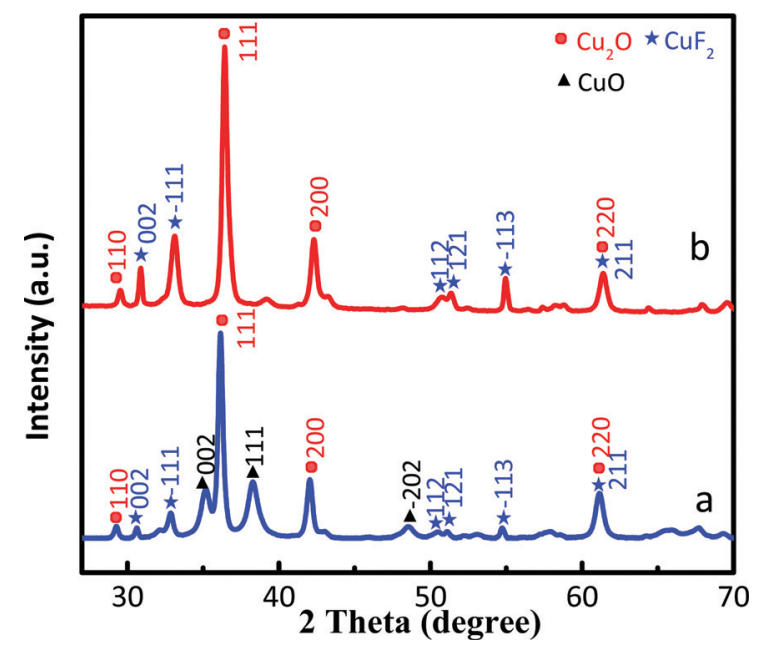

Fig. 2 XRD patterns of $\mathrm{Cu}_{2} \mathrm{O} / \mathrm{CuF}_{2}$ (a) and $\mathrm{Cu}_{2} \mathrm{O} / \mathrm{GO} / \mathrm{CuF}_{2}$ (b). 


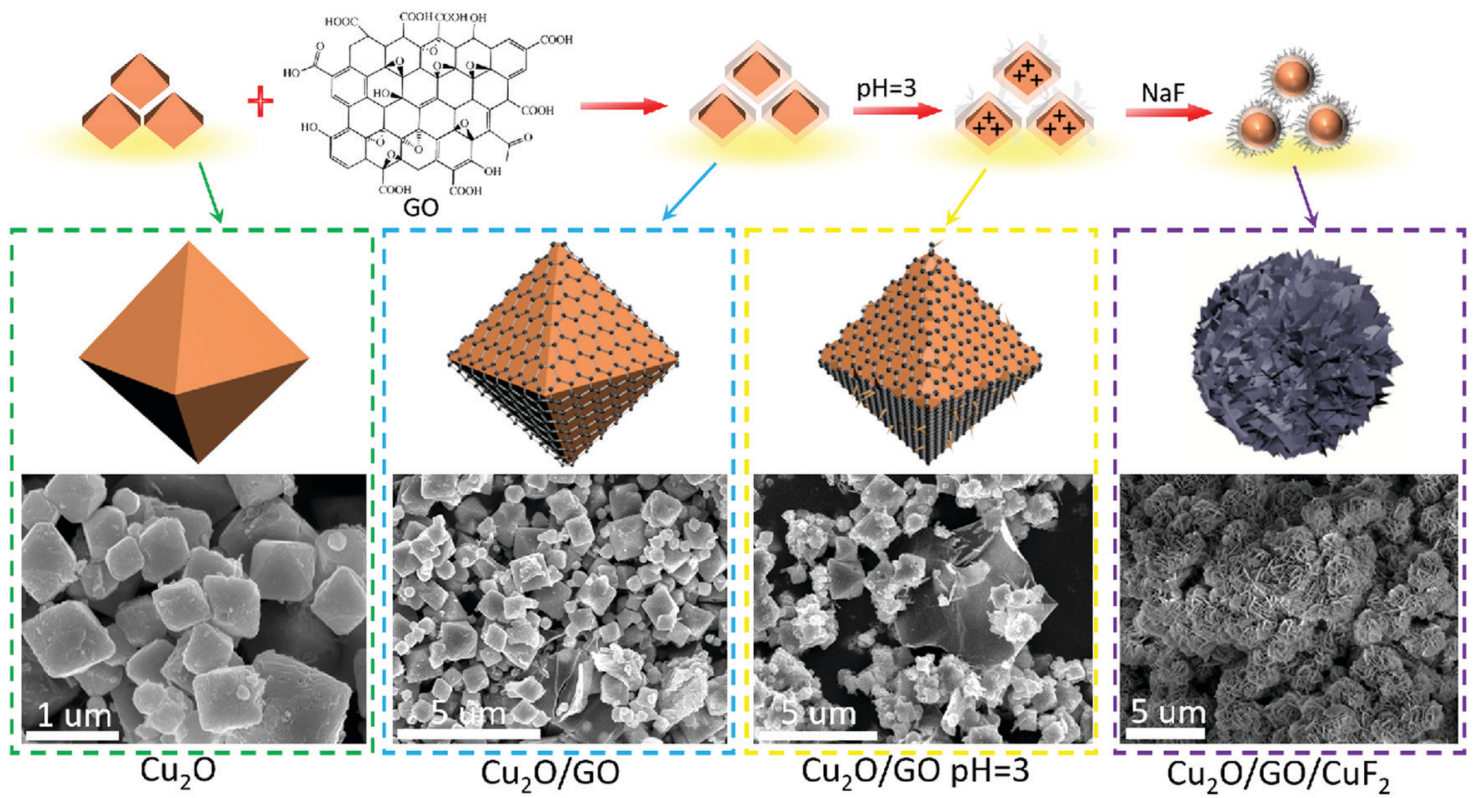

Fig. 3 Assembly scheme of the $\mathrm{Cu}_{2} \mathrm{O} / \mathrm{GO} / \mathrm{CuF}_{2}$.

with $\mathrm{HCl}$ aqueous solution, the $\mathrm{GO}$ on the $\mathrm{Cu}_{2} \mathrm{O}$ is protonated and positively charged. After $\mathrm{NaF}$ is introduced, the negatively charged fluoride ions can easily bond to the surface of the $\mathrm{Cu}_{2} \mathrm{O} / \mathrm{GO}$ through electrostatic interaction, thus $\mathrm{CuF}_{2}$ is in situ grown on the $\mathrm{Cu}_{2} \mathrm{O} / \mathrm{GO}$. It further facilitates the interaction between components, especially, the interaction between $\mathrm{Cu}_{2} \mathrm{O}$ and $\mathrm{CuF}_{2}$, thereby the special $\mathrm{Cu}_{2} \mathrm{O} / \mathrm{GO} / \mathrm{CuF}_{2}$ nanocomposite is obtained. This will be further confirmed by the results in Fig. 4-6.

\subsection{The composition and interaction in the fabricated $\mathrm{Cu}_{2} \mathrm{O} /$ $\mathrm{GO} / \mathrm{CuF}_{2}$ nanocomposite}

The composition and element distribution of the composite were tested based on the region shown in Fig. 4a. It is observed that $\mathrm{Cu}, \mathrm{O}, \mathrm{F}$ and $\mathrm{C}$ elements are present in the composite (Fig. 4b-e), which is related to theoretical composition of the $\mathrm{Cu}_{2} \mathrm{O} / \mathrm{GO} / \mathrm{CuF}_{2}$ nanocomposite. In addition, the maps of $\mathrm{Cu}, \mathrm{O}$, $\mathrm{F}$ and $\mathrm{C}$ elements shown in Fig. 4(b-e) correspond to the SEM image shown in Fig. 4a. In particular, the distribution of $\mathrm{F}$

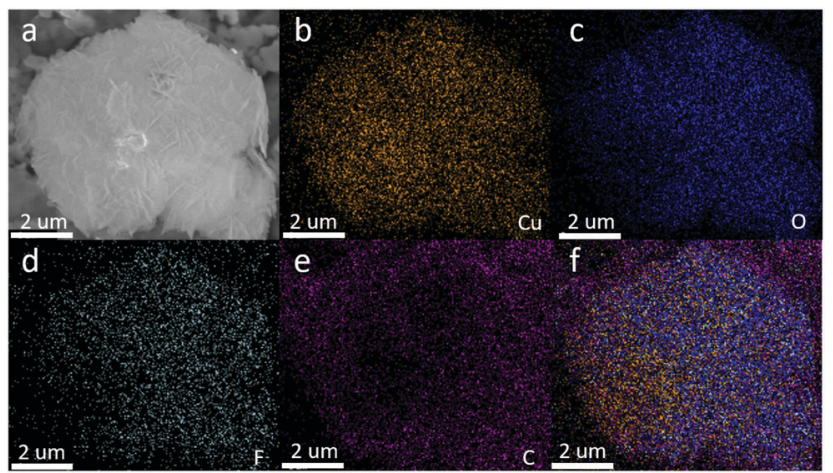

Fig. 4 (a) Energy-filtered SEM image of the nanocomposite. Element maps: (b) $\mathrm{Cu}$; (c) $\mathrm{O}$; (d) $\mathrm{F}$; (e) $\mathrm{C}$ and (f) overlying mapping of all elements. coincides well with that of the $\mathrm{Cu}$. Additionally, $\mathrm{C}$ corresponds to $\mathrm{GO}$, which indicates the presence of GO in the composite. According to the map of $\mathrm{C}$, it shows that GO is mainly distributed at the periphery of the map. Furthermore, the map of $\mathrm{F}$ (representing $\mathrm{CuF}_{2}$ ) is in agreement with that of $\mathrm{C}$ (representing GO). This is indirect evidence for the formation of $\mathrm{Cu}_{2} \mathrm{O} / \mathrm{CuF}_{2}$ heterojunction induced by $\mathrm{GO}$. The result is consistent with that in Fig. 1.

In order to study the composition and binding state of the prepared nanocomposite, XPS was measured (Fig. 5). From the survey spectrum (Fig. 5A), the peaks assigned to $\mathrm{C}, \mathrm{O}, \mathrm{Cu}$ and $\mathrm{F}$ elements are observed, which is in agreement with the elemental composition of the $\mathrm{Cu}_{2} \mathrm{O} / \mathrm{GO} / \mathrm{CuF}_{2}$ nanocomposite. From high resolution XPS image of $\mathrm{Cu} 2 \mathrm{p}$ (Fig. 5B), the binding energies at $932.7 \mathrm{eV}$ and $952.6 \mathrm{eV}$ are found to correspond to $\mathrm{Cu} 2 \mathrm{p}_{3 / 2}$ and $\mathrm{Cu} 2 \mathrm{p}_{1 / 2}$ of $\mathrm{Cu}^{+}$, respectively, indicating the presence of $\mathrm{Cu}^{+}$in the composite. ${ }^{29}$ It is consistent with the characterizations of TEM image and XRD pattern. In addition, the shake-up peaks at $935.0 \mathrm{eV}, 942.6 \mathrm{eV}$ and $955.0 \mathrm{eV}$, and the satellite peaks at 944.4 and $962.9 \mathrm{eV}$ attributed to the characteristic peaks of $\mathrm{Cu}^{2+}$ are observed, ${ }^{30}$ indicating that a small amount of $\mathrm{CuO}$ is present in the nanocomposite. It can be detected by XPS (Fig. 5B) and not by XRD (Fig. 2 b), probably because XRD is a means of analyzing the structure of a material with lower sensitivity, while XPS can sensitively survey elemental composition on the surface of a material. ${ }^{23}$ Compared to the peak at $934.6 \mathrm{eV}$ in pure $\mathrm{Cu}_{2} \mathrm{O}$, the peak at $932.7 \mathrm{eV}$ in the nanocomposite is shifted towards lower binding energy. It indicates that the electron density is enhanced in the nanocomposite, which is likely to obtain more photoproduced charges that can be excited in photocatalysis. ${ }^{31}$ In the case of the $\mathrm{Cu}_{2} \mathrm{O} / \mathrm{GO} / \mathrm{CuF}_{2}$ nanocomposite, the $\mathrm{O}$ 1s spectrum shows two peaks centered at 529.7 and $531.7 \mathrm{eV}$ (Fig. 5C). The peak at $529.7 \mathrm{eV}$ is due to the oxygen in the $\mathrm{Cu}_{2} \mathrm{O}$ crystal lattice. ${ }^{32}$ The peak at $531.7 \mathrm{eV}$ is commonly ascribed to the surface oxygen 


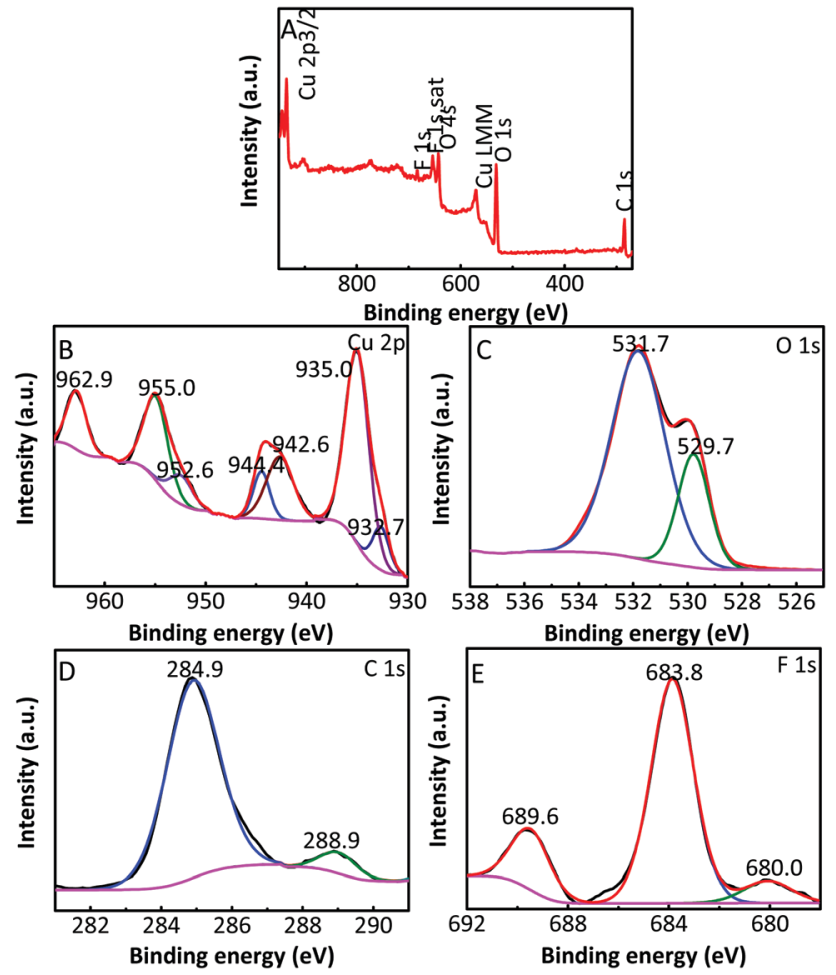

Fig. 5 (A) Typical survey XPS of the $\mathrm{Cu}_{2} \mathrm{O} / \mathrm{GO} / \mathrm{CuF}_{2}$; high resolution XPS of (B) Cu 2p, (C) O 1s, (D) C 1s and (E) F 1s
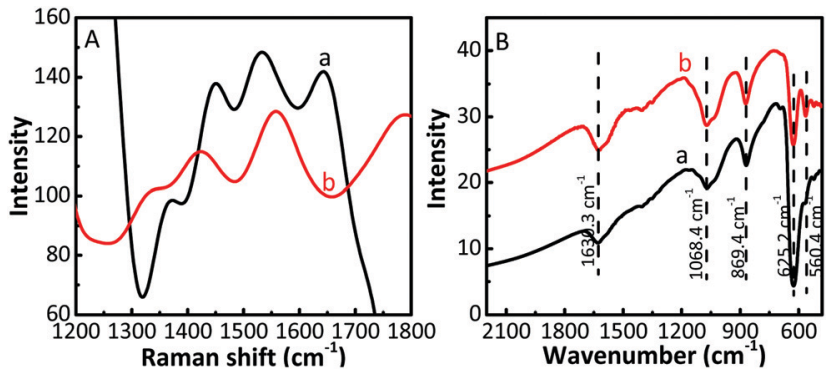

Fig. 6 (A) Raman spectra and (B) FTIR spectra of samples. (a) $\mathrm{Cu}_{2} \mathrm{O} / \mathrm{CuF}_{2}$ and (b) $\mathrm{Cu}_{2} \mathrm{O} / \mathrm{GO} / \mathrm{CuF}_{2}$.

complexes of carbon phase from GO. ${ }^{33}$ In the spectrum of $\mathrm{C} 1 \mathrm{~s}$ (Fig. 5D), the asymmetrical C 1 s peaks at about 284.9 and $288.9 \mathrm{eV}$ suggest the co-existence of distinguishable models. The sharp peak located at $284.9 \mathrm{eV}$ is attributed to $\mathrm{sp}^{2}$-hybridized carbons $(\mathrm{C}-\mathrm{C})^{34}$ while the relatively weak peak at $288.9 \mathrm{eV}$ is ascribed to $-\mathrm{COOH} .{ }^{35}$ In the spectrum of Fls (Fig. $5 \mathrm{E}$ ), the peaks at 680.0 and $689.6 \mathrm{eV}$ correspond to fluorine atoms, while the shoulder peak at $683.8 \mathrm{eV}$ is assigned to $\mathrm{CuF}_{2} \cdot{ }^{36}$ Compared to the pure $\mathrm{Cu}_{2} \mathrm{O}(529.9 \mathrm{eV})$ and $\mathrm{CuF}_{2}(684.5 \mathrm{eV})$, the binding energies for $\mathrm{O} 1 \mathrm{~s}$ and $\mathrm{F} 1 \mathrm{~s}$ are negatively shifted in the $\mathrm{Cu}_{2} \mathrm{O} / \mathrm{GO} / \mathrm{CuF}_{2}$. It indicates an increase of the electron density in $\mathrm{Cu}_{2} \mathrm{O}$ and $\mathrm{CuF}_{2}$, which is the result of the electron transfer from $\mathrm{GO}$ to $\mathrm{Cu}_{2} \mathrm{O} / \mathrm{CuF}_{2} \cdot{ }^{36-38}$ It is beneficial to improve the photocatalytic performance of the composite.

The Raman spectra and infrared spectra of the samples were measured at room temperature. Compared with bare $\mathrm{Cu}_{2} \mathrm{O}$
(Fig. S2A, ESI $\dagger$ ), the Raman intensity of the $\mathrm{Cu}_{2} \mathrm{O} / \mathrm{CuF}_{2}$ increases significantly, and all peaks are blue-shifted (Fig. 6A), indicating that the heterojunction has been successfully prepared. ${ }^{39}$ The $\mathrm{Cu}_{2} \mathrm{O} / \mathrm{GO} / \mathrm{CuF}_{2}$ shows two prominent peaks at approximately $1351 \mathrm{~cm}^{-1}$ and $1558 \mathrm{~cm}^{-1}$, corresponding to the D and $\mathrm{G}$ bands of GO, respectively. It further shows the presence of GO in the composite. The generation of the $\mathrm{G}$ band is because of the in-plane stretching motion of the symmetric $\mathrm{sp}^{2} \mathrm{C}-\mathrm{C}$ bond of GO, and the D band is related to the structural defects generated in the GO fragments during graphite exfoliation. ${ }^{40}$ Compared with the D band (about $1353 \mathrm{~cm}^{-1}$ ) and $\mathrm{G}$ band (about $1580 \mathrm{~cm}^{-1}$ ) of bare GO (Fig. S2A, ESI $\dagger$ ), the two bands shift towards a low wavenumber. It is reported that the $\mathrm{G}$ band and the $\mathrm{D}$ band will move towards a low wavenumber when graphene is subjected to external interaction. ${ }^{39}$ In addition, charge doping and the change of Fermi level of graphene will also have a significant effect on its Raman characteristic peaks and the internal electron-phonon coupling. ${ }^{41}$ Therefore, it is suggested that there exists a strong interaction between $\mathrm{Cu}_{2} \mathrm{O}$, $\mathrm{GO}$ and $\mathrm{CuF}_{2}$, which will have a great influence on the charge separation in the nanocomposite.

Additionally, in the FTIR of the samples (Fig. 6B and Fig. S2B, ESI $\dagger$ ), the band at $869.1 \mathrm{~cm}^{-1}$ corresponding to the vibration of $\mathrm{Cu}-\mathrm{F}$ can be observed in the FTIR spectrum of the $\mathrm{Cu}_{2} \mathrm{O} / \mathrm{GO} / \mathrm{CuF}_{2}$ (Fig. 6B), the vibration at $560.4 \mathrm{~cm}^{-1}$ can be designated as a $\mathrm{Cu}-\mathrm{O}$ stretching vibration, ${ }^{42}$ and the band at $1068.4 \mathrm{~cm}^{-1}$ belonging to the vibration of $\mathrm{O}-\mathrm{Cu}-\mathrm{F}$ is also observed. ${ }^{43}$ However, the two bands are not observed in the spectra of the two comparisons (Fig. S2, ESI $\dagger$ ). This is attributed to the formation of the $\mathrm{Cu}_{2} \mathrm{O} / \mathrm{GO} / \mathrm{CuF}_{2}$ nanocomposite. The result is in line with the results shown in Fig. 1-5.

\subsection{Photocatalytic hydrogen evolution over the prepared nanocomposite}

The photocatalytic activity and stability of the as-prepared samples were tested via photocatalytic hydrogen production with TEOA as a sacrificial agent and under the irradiation of a $300 \mathrm{~W}$ xenon lamp. As shown in Fig. 7A and Fig. S3 (ESI $\dagger$ ), the samples can achieve steady hydrogen generation. The activity is in the order of $\mathrm{CuF}_{2}<\mathrm{GO}<\mathrm{Cu}_{2} \mathrm{O} \approx \mathrm{Cu}_{2} \mathrm{O} / \mathrm{CuF}_{2}$ (simply mixed) (Fig. S3, ESI $\dagger$ ) $<\mathrm{Cu}_{2} \mathrm{O} / \mathrm{GO}<\mathrm{Cu}_{2} \mathrm{O} / \mathrm{GO} / \mathrm{CuF}_{2}$ (simply mixed) $<$ $\mathrm{Cu}_{2} \mathrm{O} / \mathrm{GO} / \mathrm{CuF}_{2}$ (Fig. 7A). In particular, compared with $\mathrm{Cu}_{2} \mathrm{O}$ / $\mathrm{CuF}_{2}$, the sample by directly mixing $\mathrm{Cu}_{2} \mathrm{O}, \mathrm{GO}$ and $\mathrm{CuF}_{2}$ (denoted as $\mathrm{Cu}_{2} \mathrm{O} / \mathrm{GO} / \mathrm{CuF}_{2}$ (simply mixed)) only shows a slightly improved photocatalytic activity. In contrast, the $\mathrm{Cu}_{2} \mathrm{O} / \mathrm{GO} / \mathrm{CuF}_{2}$ heterostructure obtained via in situ growth shows a significantly enhanced photocatalytic activity (increased approximately $292.5 \%$ ), which exceeds the rate of the $\mathrm{Cu}_{2} \mathrm{O} / \mathrm{GO} / \mathrm{CuF}_{2}$ (simply mixed) by more than two times. In addition, the hydrogen production over the $\mathrm{Cu}_{2} \mathrm{O} / \mathrm{GO} / \mathrm{CuF}_{2}$ composite is higher than the sum of $\mathrm{Cu}_{2} \mathrm{O} / \mathrm{CuF}_{2}$ and $\mathrm{GO}$ (Fig. 7B). These results indicate that there exists a synergetic effect between $\mathrm{Cu}_{2} \mathrm{O}, \mathrm{CuF}_{2}$ and GO. In particular, after the introduction of GO, the formation of the $\mathrm{Cu}_{2} \mathrm{O} / \mathrm{CuF}_{2}$ heterojunction with special morphology, and increased $\mathrm{CuF}_{2}$ (Fig. 1 and 2) are both beneficial to improve the photocatalytic activity of the $\mathrm{Cu}_{2} \mathrm{O} / \mathrm{GO} / \mathrm{CuF}_{2}$. 

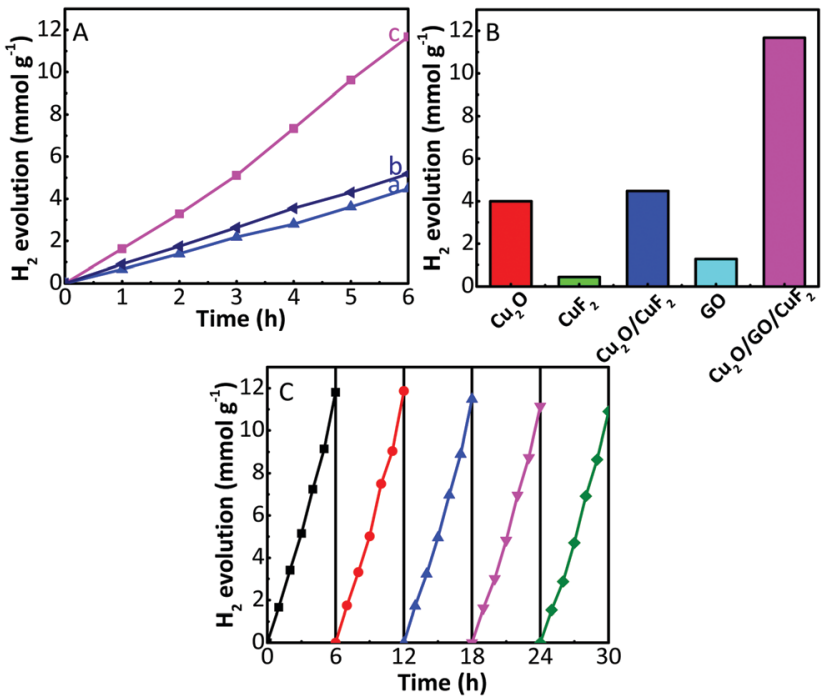

Fig. 7 (A) Typical time courses of $\mathrm{H}_{2}$ generation over the as-prepared $\mathrm{Cu}_{2} \mathrm{O} / \mathrm{CuF}_{2}$ (a), $\mathrm{Cu}_{2} \mathrm{O} / \mathrm{GO} / \mathrm{CuF}_{2}$ (simply mixed) (b), and $\mathrm{Cu}_{2} \mathrm{O} / \mathrm{GO} / \mathrm{CuF}_{2}$ (c); (B) comparison of hydrogen evolution over various samples irradiated for $6 \mathrm{~h}$; (C) cycling measurements of $\mathrm{H}_{2}$ generation over the $\mathrm{Cu}_{2} \mathrm{O} / \mathrm{GO} / \mathrm{CuF}_{2}$ nanocomposite.

The reusability of photocatalysts is one of the most important factors to be considered in catalytic research and practical applications. Therefore, photocatalytic stability of the $\mathrm{Cu}_{2} \mathrm{O}$ / $\mathrm{GO} / \mathrm{CuF}_{2}$ nanocomposite was investigated. Five cycles were carried out, and each cycle lasted for 6 h. Fig. 7C displays hydrogen production performance in each photocatalytic run. It is observed that the amount of hydrogen produced is almost unchanged in the first three cycles. After three consecutive usages for hydrogen evolution, the amount of hydrogen produced decreases slightly.

To investigate the reason for the slight decrease in hydrogen production after the third cycle, the photocatalyst was collected after five cycles, and its XRD pattern was obtained. Compared with the XRD of the as-prepared $\mathrm{Cu}_{2} \mathrm{O} / \mathrm{GO} / \mathrm{CuF}_{2}$, the (002), (-111), (-113) crystal planes corresponding to $\mathrm{CuF}_{2}$ were reduced while the (211) crystal plane of $\mathrm{CuF}_{2}$ at $2 \theta=61.3^{\circ}$ (JCPDS: 42-1244) was observed in the recycled $\mathrm{Cu}_{2} \mathrm{O} / \mathrm{GO} / \mathrm{CuF}_{2}$ (Fig. 8A). Moreover, the photocatalytic activity of the recycled $\mathrm{Cu}_{2} \mathrm{O} / \mathrm{GO} / \mathrm{CuF}_{2}$ is still higher than that of the other as-prepared comparisons, especially the as-prepared $\mathrm{Cu}_{2} \mathrm{O} / \mathrm{GO}$ (Fig. 7A, B and Fig. S3, ESI $\dagger$ ). Therefore, the slight decrease of hydrogen production in the third cycle could be attributed to the structural and crystalline changes of the $\mathrm{CuF}_{2}$ in the $\mathrm{Cu}_{2} \mathrm{O} / \mathrm{GO} / \mathrm{CuF}_{2}$. However, the changes have little effect on the activity of the nanocomposite.

In addition, in the XPS of the recycled $\mathrm{Cu}_{2} \mathrm{O} / \mathrm{GO} / \mathrm{CuF}_{2}$ (Fig. 8B), it is observed that the composition of the nanocomposite is unchanged compared with that of the as-prepared $\mathrm{Cu}_{2} \mathrm{O} / \mathrm{GO} / \mathrm{CuF}_{2}$ (Fig. 5A). In Fig. 8C, the binding energy of $\mathrm{Cu} 2 \mathrm{p} 1 /$

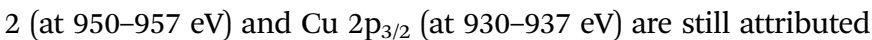
to those of $\mathrm{Cu}^{2+}$ and $\mathrm{Cu}^{+},{ }^{30}$ and thus the valence state of $\mathrm{Cu}$ is hardly changed compared with those of the as-prepared sample (Fig. 5). The slight shift of the $\mathrm{Cu} 2 \mathrm{p}$ including $\mathrm{O}$ 1s peaks towards
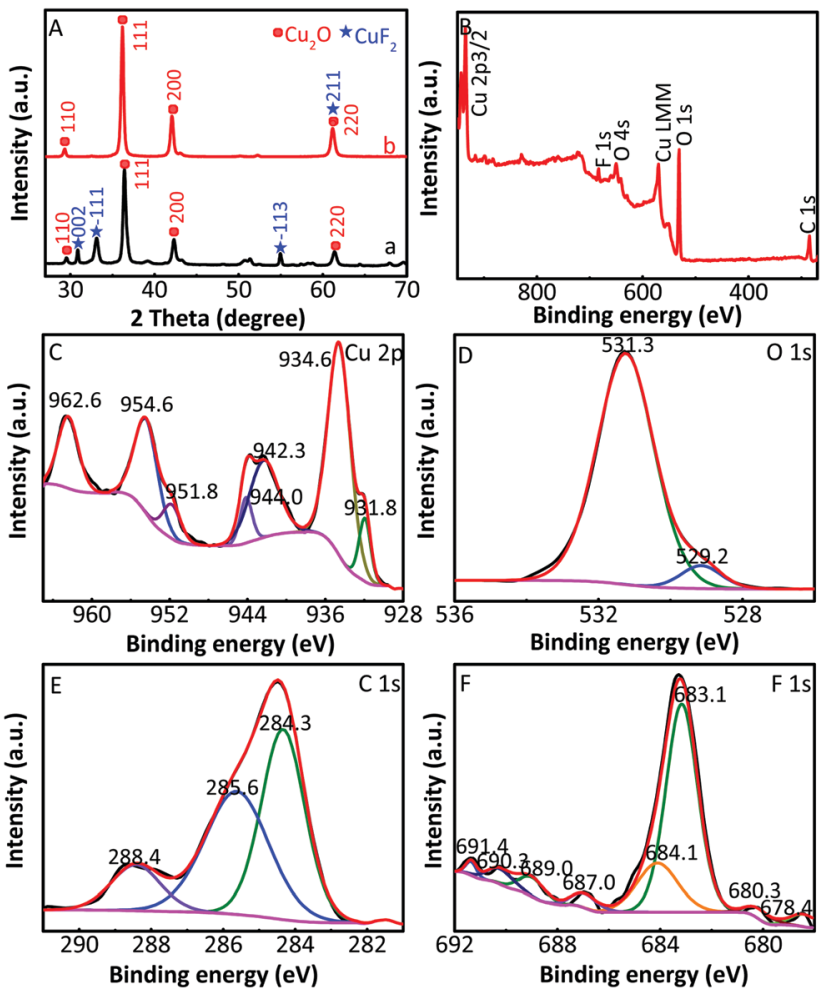

Fig. 8 (A) XRD patterns of the as-prepared $\mathrm{Cu}_{2} \mathrm{O} / \mathrm{GO} / \mathrm{CuF}_{2}$ (a) and that after recycling (b); (B) typical survey XPS of the $\mathrm{Cu}_{2} \mathrm{O} / \mathrm{GO} / \mathrm{CuF}_{2}$ nanocomposite; high resolution XPS of (C) Cu 2p, (D) O 1s, (E) C 1s and (F) F 1s after recycling.

the low binding energy is observed, which can be attributed to the change of electron density around $\mathrm{Cu}$ and $\mathrm{O} .{ }^{31}$ Besides, the peak of $\mathrm{O} 1 \mathrm{~s}$ at $529.7 \mathrm{eV}$ for the as-prepared $\mathrm{Cu}_{2} \mathrm{O} / \mathrm{GO} / \mathrm{CuF}_{2}$ is decreased, indicating that the content of $\mathrm{O}$ is reduced in the recycled $\mathrm{Cu}_{2} \mathrm{O} / \mathrm{GO} / \mathrm{CuF}_{2}$. Moreover, the peak of $\mathrm{C} 1 \mathrm{~s}$ at $284.9 \mathrm{eV}$ is divided into two peaks of 285.6 and $284.3 \mathrm{eV}$ after recycling. In XPS spectrum of $\mathrm{F} 1 \mathrm{~s}$ of the recycled $\mathrm{Cu}_{2} \mathrm{O} / \mathrm{GO} / \mathrm{CuF}_{2}$, the peaks at 689.0, 687.0, 684.1 and 680.3 eV belong to $\mathrm{CuF}_{2}$, while the peaks at 683.1 and $678.4 \mathrm{eV}$ are attributed to fluorine atoms, and the peaks at 690.3 and $691.4 \mathrm{eV}$ are assigned to $\mathrm{C}_{6} \mathrm{~F}_{6} \cdot{ }^{36,44}$ The result indicates that a small amount of $\mathrm{C}_{6} \mathrm{~F}_{6}$ could be produced after several recycle runs. This was not observed in XRD images, probably due to the low crystallinity and small amount. Although a small amount of $\mathrm{C}_{6} \mathrm{~F}_{6}$ could be generated during the recycle, the activity of the nanocomposite is changed little after five recycle runs. Therefore, it is concluded that the $\mathrm{Cu}_{2} \mathrm{O} / \mathrm{GO} / \mathrm{CuF}_{2}$ nanocomposite is a relatively stable photocatalyst.

\subsection{Photocatalytic mechanism of the $\mathrm{Cu}_{2} \mathrm{O} / \mathrm{GO} / \mathrm{CuF}_{2}$ nanocomposite}

In order to analyse the reason for the enhanced activity of the $\mathrm{Cu}_{2} \mathrm{O} / \mathrm{GO} / \mathrm{CuF}_{2}$ photocatalyst, solid diffuse reflection spectra and electrochemical impedance spectra of samples are investigated. Fig. 9A shows the diffuse reflection spectra. An enhanced visible absorption is observed in the $\mathrm{Cu}_{2} \mathrm{O} / \mathrm{CuF}_{2}$. Importantly, significant absorption is seen at about $675 \mathrm{~nm}$ in the $\mathrm{Cu}_{2} \mathrm{O} / \mathrm{GO} / \mathrm{CuF}_{2}$ 
composite, which is beneficial for enhancing the photocatalytic activity of the nanocomposite. Moreover, it shows a different spectrum and absorption edge from those of the $\mathrm{Cu}_{2} \mathrm{O} / \mathrm{CuF}_{2}$, implying that some $\mathrm{CuF}_{2}$ could be incorporated into the $\mathrm{Cu}_{2} \mathrm{O}$ induced by GO. The close contact is very beneficial to improve the photocatalytic activity.

It is known that the property of an interface has a close relationship with transfer efficiency of charges. Thus, investigating charge separation and transfer across the semiconductor interface is vital. Electrochemical impedance (EIS) is a powerful tool for exploring the charge transfer at the interface of materials. The arc radius of an impedance spectrum can represent the interfacial resistance, which can be used to demonstrate separation and transfer of charges. The smaller the radius of the arc, the easier the electron transfer, and generally, higher the photocatalytic activity. As shown in Fig. 9B, the order of the arc radius of the samples is $\mathrm{Cu}_{2} \mathrm{O}>\mathrm{Cu}_{2} \mathrm{O} / \mathrm{CuF}_{2}>\mathrm{Cu}_{2} \mathrm{O} / \mathrm{GO} / \mathrm{CuF}_{2}$, thus the $\mathrm{Cu}_{2} \mathrm{O} / \mathrm{GO} / \mathrm{CuF}_{2}$ nanocomposite possesses the smallest interfacial resistance. It is deduced that the effective interaction arising from $\mathrm{Cu}_{2} \mathrm{O}, \mathrm{GO}$ and $\mathrm{CuF}_{2}$ is responsible for the low interfacial resistance, which is helpful in promoting charge transfer and improving photocatalytic activity.

The photo-generated electron transfer was studied through the photocurrent spectra. As shown in Fig. 9C, under light conditions, the photocurrent response of the composites is lower than that of $\mathrm{Cu}_{2} \mathrm{O}$. It is known that a photocurrent is formed because of the transition of photo-generated electrons to the underlying FTO through the grain boundaries of the composite coated on the electrode. ${ }^{45}$ In the $\mathrm{Cu}_{2} \mathrm{O} / \mathrm{GO}$ or $\mathrm{Cu}_{2} \mathrm{O}$ / $\mathrm{GO} / \mathrm{CuF}_{2}$ electrode, the electrons generated are transferred to FTO through a series of particle boundaries, and then are collected to produce the photocurrent. Although the light
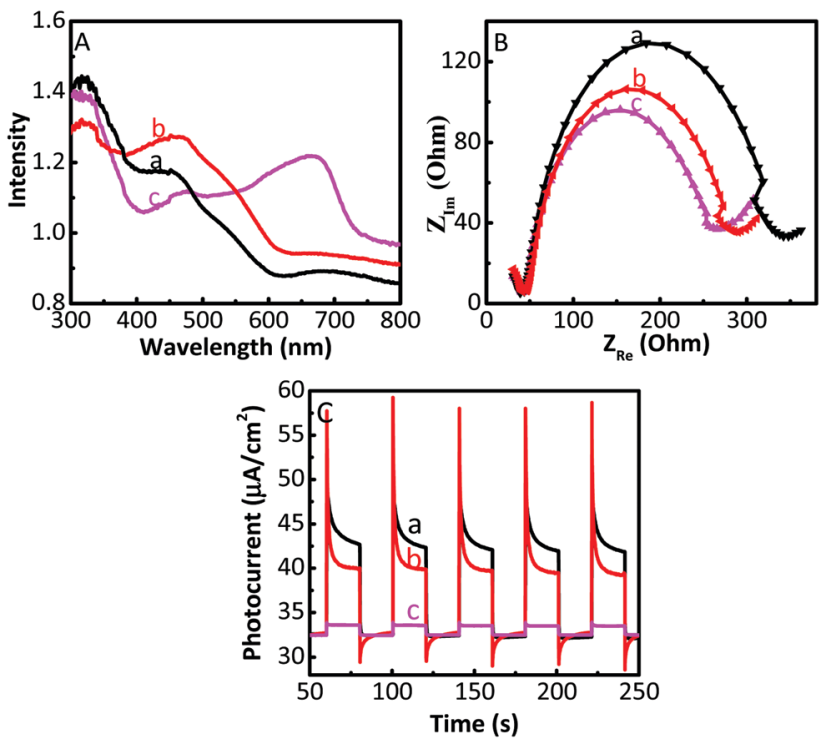

Fig. 9 (A) Solid diffuse reflection spectra of $\mathrm{Cu}_{2} \mathrm{O}(\mathrm{a}), \mathrm{Cu}_{2} \mathrm{O} / \mathrm{CuF}_{2}$ (b) and $\mathrm{Cu}_{2} \mathrm{O} / \mathrm{GO} / \mathrm{CuF}_{2}$ (c); (B) Nyquist plots of the electrochemical impedance spectra of $\mathrm{Cu}_{2} \mathrm{O}$ (a), $\mathrm{Cu}_{2} \mathrm{O} / \mathrm{CuF}_{2}$ (b) and $\mathrm{Cu}_{2} \mathrm{O} / \mathrm{GO} / \mathrm{CuF}_{2}$ (c); (C) transient photocurrent response of $\mathrm{Cu}_{2} \mathrm{O}(\mathrm{a}), \mathrm{Cu}_{2} \mathrm{O} / \mathrm{GO}$ (b) and $\mathrm{Cu}_{2} \mathrm{O} / \mathrm{GO} / \mathrm{CuF}_{2}$ (c).

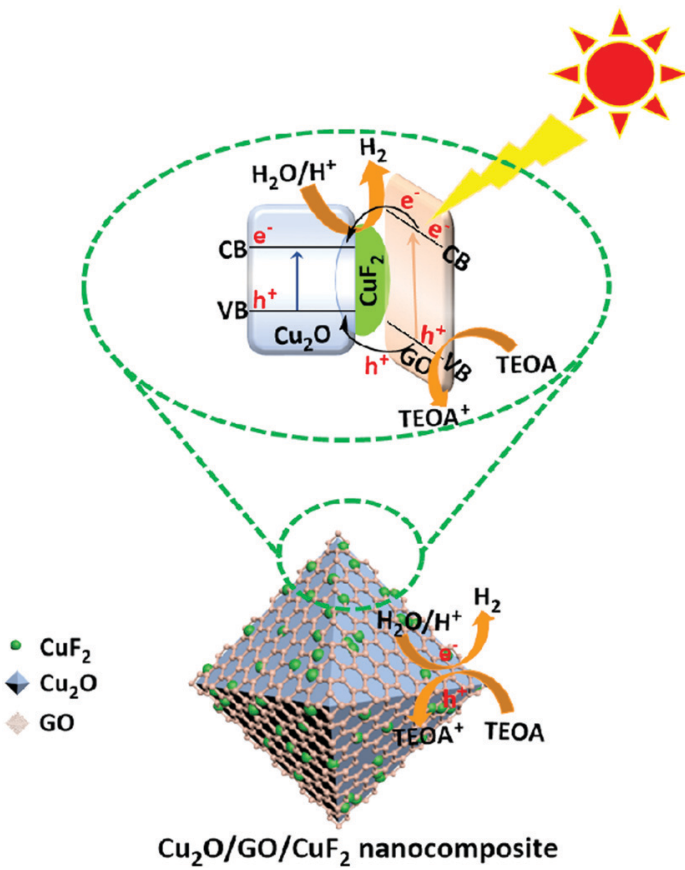

Scheme 2 Suggested scheme of photo-produced charges in the $\mathrm{Cu}_{2} \mathrm{O} /$ $\mathrm{GO} / \mathrm{CuF}_{2}$ nanocomposite

absorption of $\mathrm{Cu}_{2} \mathrm{O} / \mathrm{GO}$ or $\mathrm{Cu}_{2} \mathrm{O} / \mathrm{GO} / \mathrm{CuF}_{2}$ is higher, the electrons that jump over the particle boundary in the electrode are trapped by GO, which reduces the photocurrent. ${ }^{45}$ That is, the $\mathrm{GO}$ layer on $\mathrm{Cu}_{2} \mathrm{O}$ is helpful for the interfacial electron transfer in the composite, but the retention of electrons in the GO reduces the photocurrent in the electrode systems.

On the basis of the above experimental results, a possible photocatalytic mechanism is proposed (Scheme 2). It is known that the numbers of excited electrons at the interface between water and photocatalyst is critical to photocatalytic activity. ${ }^{46} \mathrm{In}$ the $\mathrm{Cu}_{2} \mathrm{O} / \mathrm{GO} / \mathrm{CuF}_{2}$ nanocomposite, $\mathrm{GO}$ and $\mathrm{Cu}_{2} \mathrm{O}$ can both be excited according to their absorption spectra (not shown here) after irradiation, and thus more photo-generated electrons are produced. The conduction band level of $\mathrm{Cu}_{2} \mathrm{O}$ is lower than that of $\mathrm{GO},{ }^{47}$ so electrons can be transferred from $\mathrm{GO}$ to $\mathrm{Cu}_{2} \mathrm{O} / \mathrm{CuF}_{2}$. Subsequently, $\mathrm{e}^{-} / \mathrm{h}^{+}$is effectively separated on the special heterointerface between $\mathrm{Cu}_{2} \mathrm{O}$ and $\mathrm{CuF}_{2}$. After that, water molecules are reduced by the photo-produced electrons, and $\mathrm{H}_{2}$ is evolved. The holes are consumed by TEOA. In this case, an enhanced visible absorption (Fig. 6), strong synergetic effect between $\mathrm{Cu}_{2} \mathrm{O}, \mathrm{CuF}_{2}$ and $\mathrm{GO}$ (Fig. 7), and decreased interfacial resistance from the special heterojunction (Fig. 9), result in a significant enhancement of photocatalytic activity in the $\mathrm{Cu}_{2} \mathrm{O} / \mathrm{GO} / \mathrm{CuF}_{2}$ nanocomposite.

\section{Conclusions}

Induced by $\mathrm{GO}$, a special $\mathrm{Cu}_{2} \mathrm{O} / \mathrm{CuF}_{2}$ heterojunction was fabricated in situ. It was found that GO can promote the formation of a uniform nanoflower-like $\mathrm{Cu}_{2} \mathrm{O} / \mathrm{CuF}_{2}$ heterojunction, increase the crystalline of $\mathrm{CuF}_{2}$, and reduce the $\mathrm{CuO}$ phase with lower activity of 
hydrogen generation. Moreover, visible absorption and the separation of photogenerated electrons/holes can be effectively enhanced by fabricating the special heterojunction. Importantly, the photocatalytic activity of the $\mathrm{Cu}_{2} \mathrm{O} / \mathrm{GO} / \mathrm{CuF}_{2}$ nanocomposite increased by $260.4 \%$ and $139.6 \%$ compared to $\mathrm{Cu}_{2} \mathrm{O} / \mathrm{CuF}_{2}$ and $\mathrm{Cu}_{2} \mathrm{O} / \mathrm{GO}$, respectively. It exceeded the rate of the $\mathrm{Cu}_{2} \mathrm{O} / \mathrm{GO} / \mathrm{CuF}_{2}$ (simply mixed) by more than two times. The photocatalytic mechanism showed that enhanced visible absorption, decreased interfacial resistance from the special heterojunction, and strong synergetic effect between $\mathrm{Cu}_{2} \mathrm{O}, \mathrm{CuF}_{2}$ and $\mathrm{GO}$, were all helpful to significantly improve the photocatalytic performance of the $\mathrm{Cu}_{2} \mathrm{O} / \mathrm{GO} / \mathrm{CuF}_{2}$ nanocomposite. Owing to the advantages of low cost and easy operation, the fabrication of the nanocomposite is expected to provide some ideas for preparing other semiconductor photocatalysts.

\section{Conflicts of interest}

The authors declare that we have no known competing financial interests or personal relationships that could have appeared to influence the work reported in this paper.

\section{Acknowledgements}

This work was financially supported by National Natural Science Foundation of China (No. 21771125, 21301118 and 21305092).

\section{References}

1 X. Guo, K. Hu, M. Chu, Y. Li, J. Bian, Y. Qu, X. Chu, F. Yang, Q. Zhao, C. Qin and L. Jing, ChemSusChem, 2020, 13, 3707-3717.

2 X. Wu, H. Ma, W. Zhong, J. Fan and H. Yu, Appl. Catal., B, 2020, 271, 1-8.

3 Y.-S. Chang, P.-Y. Hsieh, T.-F. Chang, C.-Y. Chen, M. Sone and Y.-J. Hsu, J. Mater. Chem. A, 2020, 8, 13971-13979.

4 D. Ma, Z. Wang, J.-W. Shi, Y. Zou, Y. Lv, X. Ji, Z. Li, Y. Cheng and L. Wang, J. Mater. Chem. A, 2020, 8, 11031-11042.

5 L. Pan, J. H. Kim, M. T. Mayer, M.-K. Son, A. Ummadisingu, J. S. Lee, A. Hagfeldt, J. Luo and M. Grätzel, Nat. Catal., 2018, 1, 412-420.

6 P. D. Tran, S. K. Batabyal, S. S. Pramana, J. Barber, L. H. Wong and S. C. Loo, Nanoscale, 2012, 4, 3875-3878.

7 M. Mousavi-Kamazani, Z. Zarghami, R. Rahmatolahzadeh and M. Ramezani, Adv. Powder Technol., 2017, 28, 2078-2086.

8 Y.-H. Zhang, X.-L. Cai, Y.-L. Li, M.-M. Liu, C.-L. Ding, J.-L. Chen and S.-M. Fang, Chem. Phys. Lett., 2019, 734, 136748.

9 J. A. Aramburu and M. Moreno, Phys. Chem. Chem. Phys., 2019, 21, 11714-11723.

10 C. Czekelius and E. Carreira, Org. Lett., 2004, 6, 4575-4577. 11 J. d elPozo, J. A. Casares and P. Espinet, Chem. - Eur. J., 2016, 22, 4274-4284.
12 S. Zhu, Y. Zhang, X. Qian, X. Wang and W. Su, Appl. Surf. Sci., 2020, 504, 1-2.

13 D. Liu, S. Zhang, J. Wang, T. Peng and R. Li, ACS Appl. Mater. Interfaces, 2019, 11, 27913-27923.

14 C. Liu, Y. Yang, W. Li, J. Li, Y. Li, Q. Shi and Q. Chen, ACS Appl. Mater. Interfaces, 2015, 7, 10763-10770.

15 C. Liu, Y. Yang, W. Li, J. Li, Y. Li and Q. Chen, Sci. Rep., 2016, 6, 1-12.

16 C. Huang, Y. Li, N. Wang, Y. Xue, Z. Zuo and H. Liu, Chem. Rev., 2018, 118, 7744-7803.

17 Z. Zuo and Y. Li, Joule, 2017, 3, 899-907.

18 L. Hui, Y. Xue, H. Yu, Y. Liu, Y. Fang and C. Xing, J. Am. Chem. Soc., 2019, 141, 10677-10683.

19 Y. Fang, Y. Xue, L. Hui, H. Yu and Y. Li, Angew. Chem., Int. Ed., 2020, 59, 2-7.

20 H. Sun, S. Liu, S. Liu and S. Wang, Appl. Catal., B, 2014, 146, 162-168.

21 J. Yang, H. Miao, J. Jing, Y. Zhu and W. Choi, Appl. Catal., B, 2021, 281, 119547.

22 X. Pan and Z. Yi, ACS Appl. Mater. Interfaces, 2015, 7, 27167-27175.

23 Q. Lei, H. Song, X. Chen, M. Li, A. Li, B. Tang and D. Zhou, RSC Adv., 2016, 6, 40683-40690.

24 R. Ge, X. Li, B. Zhuang, S.-Z. Kang, L. Qin and G. Li, Appl. Catal., B, 2017, 211, 296-304.

25 S. Gao, J. Zhang, W. Li, S. Jiao, Y. Nie, H. Fan, Z. Zeng, Q. Yu, J. Wang and X. Zhang, Chem. Phys. Lett., 2018, 692, 14-18; J. Yu and J. Ran, Energy Environ. Sci., 2011, 4, 1364-1371.

26 Q. Zhong, H. Y. Lan, M. M. Zhang, H. Zhu and M. Bu, Ceram. Int., 2020, 46, 12192-12199.

27 C. Qin, H. Li, J. Zhong, J. Li, S. Huang and L. Ma, Mater. Lett., 2021, 283, 128793-128796.

28 P. A. DeSario, C. L. Pitman, D. J. Delia, D. M. Driscoll, A. J. Maynes, J. R. Morris, A. M. Pennington, T. H. Brintlinger, D. R. Rolison and J. J. Pietron, Appl. Catal., B, 2019, 252, 205-213.

29 S. Joshi, S. J. Ippolito and M. V. Sunkara, RSC Adv., 2016, 6, 43672-43684.

30 J. He, D. Shao, L. Zheng, L. Zheng, D. Feng and J. Xu, Appl. Catal., B, 2017, 203, 917-926.

31 F. Wang, Y. Zhao, F. Feng, C. Li, F. Cao and W. Shangguan, J. Alloys Compd., 2016, 688, 632-638.

32 M. Chi, X. Sun, A. Sujan, Z. Davis and B. J. Tatarchuk, Fuel, 2019, 238, 454-461.

33 J. Zhang, J. Jiang and X. S. Zhao, J. Phys. Chem. C, 2011, 115, 6448-6454.

34 R. Al-Gaashani, A. Najjar, Y. Zakaria, S. Mansour and M. A. Atieh, Ceram. Int., 2019, 45, 14439-14448.

35 H.-S. Jang, J.-M. Yun, D.-Y. Kim, D.-W. Park, S.-I. Na and S.-S. Kim, Electrochim. Acta, 2012, 81, 301-307.

36 J. Zhu, J. Sun, S. Tian, J. Yang, J. Feng and Y. Xiong, Environ. Sci.: Nano, 2020, 7, 2723-2734.

37 Z. Zhang, L. Sun, Z. Wu, Y. Liu and S. Li, New J. Chem., 2020, 44, 6420-6427.

$38 \mathrm{~J} . \mathrm{Wu}, \mathrm{P}$. Huang, H. Fan, G. Wang and W. Liu, ACS Appl. Mater. Interfaces, 2020, 12, 30304-30312. 
39 Z. Ni, T. Yu, Y. Lu, Y. Wang, Y. Feng and Z. Shen, ACS Nano, 2008, 2, 2301-2305.

40 F. Berrellez-Reyes and S. Alvarez-Garcia, J. Phys. Chem. C, 2019, 123, 30021-30027.

41 J. Yan, Y. Zhang, P. Kim and A. Pinczuk, Phys. Rev. Lett., 2007, 98, 166802.

42 N. Saima, S. Shamaila, A. K. L. Sajjad, A. Ishaq and M. Tariq, Mater. Res. Express, 2019, 6, 1-15.
43 G. Giester and E. Libowitzky, Z. Kristallogr., 2003, 218, 351-356. 44 B. Mei, K. Han and G. Mu, ACS Catal., 2018, 8, 9154-9164.

45 Y. Park, S. Kang and W. Choi, Phys. Chem. Chem. Phys., 2011, 13, 9425-9431.

46 Z. H. Ye, G. E. M. Schukraft, A. L'Hermitte, Y. Xiong, E. Brillas, C. Petit and I. Sirés, Water Res., 2020, 184, 115986.

47 P. Wang, M. Xi, S. Kang, L. Qin, G. Li and X. Li, Int. J. Hydrogen Energy, 2020, 45, 6508-6518. 